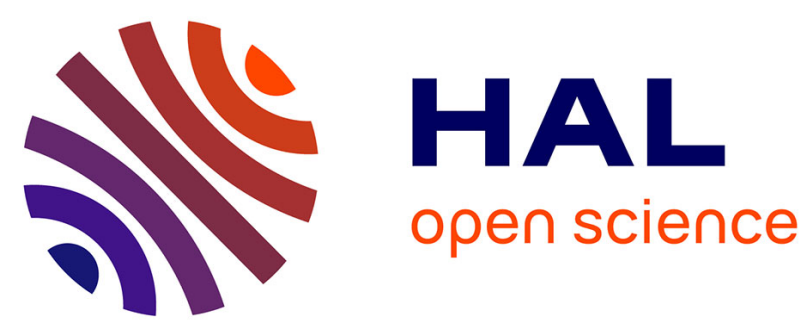

\title{
Adenosine A receptor gene () variants may increase autistic symptoms and anxiety in autism spectrum disorder
}

Christine M. Freitag, Konstantin Agelopoulos, Ellen Huy, Matthias Rothermundt, Petra Krakowitzky, Jobst Meyer, Jürgen Deckert, Alexander Gontard, Christa Hohoff

\section{To cite this version:}

Christine M. Freitag, Konstantin Agelopoulos, Ellen Huy, Matthias Rothermundt, Petra Krakowitzky, et al.. Adenosine A receptor gene () variants may increase autistic symptoms and anxiety in autism spectrum disorder. European Child and Adolescent Psychiatry, 2009, 19 (1), pp.67-74. 10.1007/s00787-009-0043-6 . hal-00535164

\section{HAL Id: hal-00535164 https://hal.science/hal-00535164}

Submitted on 11 Nov 2010

HAL is a multi-disciplinary open access archive for the deposit and dissemination of scientific research documents, whether they are published or not. The documents may come from teaching and research institutions in France or abroad, or from public or private research centers.
L'archive ouverte pluridisciplinaire HAL, est destinée au dépôt et à la diffusion de documents scientifiques de niveau recherche, publiés ou non, émanant des établissements d'enseignement et de recherche français ou étrangers, des laboratoires publics ou privés. 


\title{
Adenosine $\mathrm{A}_{2 \mathrm{~A}}$ receptor gene (ADORA2A) variants may increase autistic symptoms and anxiety in autism spectrum disorder
}

\author{
Christine M. Freitag $\cdot$ Konstantin Agelopoulos $\cdot$ Ellen Huy \\ Matthias Rothermundt · Petra Krakowitzky · Jobst Meyer · \\ Jürgen Deckert · Alexander von Gontard · Christa Hohoff
}

Received: 14 November 2008/ Accepted: 10 June 2009/Published online: 30 June 2009

(C) Springer-Verlag 2009

\begin{abstract}
Autism spectrum disorders (ASDs) are heterogeneous disorders presenting with increased rates of anxiety. The adenosine $\mathrm{A}_{2 \mathrm{~A}}$ receptor gene (ADORA2A) is associated with panic disorder and is located on chromosome 22q11.23. Its gene product, the adenosine $A_{2 A}$ receptor, is strongly expressed in the caudate nucleus, which also is involved in ASD. As autistic symptoms are increased in individuals with 22q11.2 deletion syndrome, and large 22q11.2 deletions and duplications have been observed in ASD individuals, in this study, 98 individuals with ASD and 234 control individuals were genotyped for
\end{abstract}

C. M. Freitag $(\varangle)$

Department of Child and Adolescent Psychiatry, Johann Wolfgang Goethe-Universität, Deutschordenstraße 50, 60528 Frankfurt am Main, Germany

e-mail: C.Freitag@em.uni-frankfurt.de

C. M. Freitag · E. Huy · A. von Gontard

Department of Child and Adolescent Psychiatry,

Saarland University Hospital, Homburg, Germany

M. Rothermundt · J. Deckert - C. Hohoff

Department of Psychiatry, University of Münster,

Münster, Germany

K. Agelopoulos

Institute of Pathology, University of Münster, Münster, Germany

J. Meyer

Department of Neurobehavioral Genetics, University of Trier,

Trier, Germany

P. Krakowitzky

Institute of Transfusion Medicine, University of Münster,

Münster, Germany

J. Deckert

Department of Psychiatry, University of Würzburg,

Würzburg, Germany eight single-nucleotide polymorphisms in ADORA2A. Nominal association with the disorder was observed for rs2236624-CC, and phenotypic variability in ASD symptoms was influenced by rs3761422, rs5751876 and rs35320474. In addition, association of ADORA2A variants with anxiety was replicated for individuals with ASD. Findings point toward a possible mediating role of ADORA2A variants on phenotypic expression in ASD that need to be replicated in a larger sample.

Keywords Autism spectrum disorder - ADORA2A . Anxiety · Basal ganglia · Caudate nucleus · Glutamate

\section{Introduction}

Autism spectrum disorders (ASD) are genetically as well as phenotypically heterogeneous disorders, which are defined by qualitative impairments in social interaction and communication as well as stereotyped patterns of behavior and interests [2]. In addition to autism-specific impairments, high rates of anxiety disorders are observed [13]. ASD are predominately genetically determined disorders with a heritability of $>90 \%$ [8]. Among several other chromosomal disorders, large deletions and duplications of chromosome 22q11.2 are observed in about $1 \%$ of individuals with ASD [16]. In individuals with chromosome 22q11 deletion syndrome, autistic symptoms are increased, with about 20-50\% meeting the diagnostic criteria of ASD [30]. Therefore, candidate genes in this region might either influence the phenotypic expression and severity of ASD or might even be causal in their etiology. The adenosine $\mathrm{A}_{2 \mathrm{~A}}$ receptor gene (ADORA2A) is located on 22q11.23. Studies in humans have shown an association of single variants in ADORA2A with panic disorder [7, 9], caffeine or 
D-amphetamine-induced anxiety $[1,6,11]$, as well as individually differing sleep patterns [21]. In addition, animal studies have implicated the adenosine $A_{2 A}$ receptor $\left(\mathrm{A}_{2 \mathrm{~A}} \mathrm{R}\right)$ in locomotion, anxiety, inhibition of excitatory neuronal activity and sleep regulation [12, 18]. Besides high rates of anxiety disorders, motor problems and difficulties regulating sleep are often observed in ASD individuals [13].

ADORA2A codes for the $\mathrm{A}_{2 \mathrm{~A}} \mathrm{R}$, which is expressed predominantly in enkephalin-expressing GABAergic striatopallidal neurons of the basal ganglia, with highest expression in the caudate nucleus. Here, $\mathrm{A}_{2 \mathrm{~A}}$ adenosinergic, $\mathrm{D}_{2}$ dopaminergic and glutamatergic systems interact structurally and functionally [5, 22]. As brain imaging studies strongly implicated the caudate nucleus in the pathogenesis of ASD [25], the striatal enkephalinergic system was down-regulated in an animal model of autism [23], and neuropathological studies have implicated the glutamatergic system in autism [19]. ADORA2A is a promising candidate for genetic association studies in ASD. In this case-control study, we assessed eight SNPs in ADORA2A for association with the diagnosis of ASD, as well as with phenotypic variability in autistic symptoms and history of anxiety, in a sample of 98 individuals with ASD.

\section{Methods}

Sample

A sample of 98 Caucasian individuals with ASD (8 females; $8.2 \%$ ) were recruited from an ASD specialty clinic at the Department of Child and Adolescent Psychiatry of the Saarland University Hospital, Germany. Informed consent was obtained from participants and/or parents. The study design was approved by the local ethical committee (Ärztekammer des Saarlandes, Germany).

Inclusion criteria were as follows: diagnosis of autism, Asperger syndrome or atypical autism according to DSMIV; IQ or developmental quotient $\geq 35$. The Autism Diagnostic Interview-revised (ADI-R) $[15,20]$ was conducted with the parent or primary caregiver, and the behavior of the children and adolescents was directly observed by the Autism Diagnostic Observation Schedulegeneric (ADOS-G) [4, 14]. Intelligence testing was performed by the German version of the Griffith mental developmental scales, the Snijders-Oomen non-verbal intelligence test (2.5-7) [27], the German version of the Kaufman-assessment battery for children [17] or the Wechsler scales for children or adults [28, 29]. Most participants (98\%) were first diagnosed with ASD when the genetic and phenotypic data were obtained. For 14 individuals (6 autism, 8 Asperger syndrome) detailed ADI$\mathrm{R}$ data could not be obtained, either because parents were not available or because the ADI-R was performed outside the clinical setting.

The standardized medical history included a thorough pre- and perinatal history, birth parameters, developmental milestones, presence of any medical or neurological disorder including febrile seizures, epilepsy, cerebral palsy, tuberous sclerosis, neurofibromatosis or any brain anomaly. Additionally, a thorough review of medical records and a standardized medical and neurological exam were performed, and the psychotropic/antiepileptic medication status was noted. High-resolution karyotyping as well as molecular genetic assessment of fragile-X-syndrome and chromosome 15q11-13 duplication was obtained for the majority of ASD individuals (95\%).

Exclusion criteria were as follows: IQ or developmental quotient $<35$; birth weight $<2,000 \mathrm{~g}$; structural brain anomaly; tuberous sclerosis, neurofibromatosis, cerebral palsy, any other neurological disorder with the exception of a history of febrile or epileptic seizures; microcephaly, dysmorphic features, cleft palate, cardiac anomaly, immune deficiency, chronic medical disorder; non-Caucasian parent; maternal antiepileptic or psychotropic medication during pregnancy. Individuals with a cytogenetic anomaly, fragile-X-syndrome, chromosome 15q11-13 duplication, Angelman syndrome, Prader-Willi syndrome, Rett syndrome or any other genetically diagnosed syndrome or disorder were excluded from the study. These strict exclusion criteria were chosen to improve genetic and phenotypic homogeneity of the ASD sample by exclusion of individuals with a known genetic risk factor for ASD or possible phenocopies of the disorder.

The control sample of 234 Caucasian individuals (20 females; $8.6 \%$ ) was recruited at the Institute of Transfusion Medicine of the University Hospital, Münster, Germany. In these individuals (unrelated healthy anonymous blood donors), major psychiatric, neurological or internal disorders were excluded by taking a detailed medical history, and performing a physical examination and various laboratory tests. The study was approved by the Ethical Committee of the University of Muenster and written informed consent was obtained from all participating control subjects.

\section{Genotyping}

On the basis of previous association studies $[1,6,10,11]$ and the Hapmap database (data rel 16, on NCBI B34 assembly, dbSNP b124, http://www.hapmap.org), eight SNPs (Fig. 1) were chosen to cover the long form of ADORA2A (25 kb, UCSC Genome Browser, Human Mar. 2006 Assembly) and its $\pm 10 \mathrm{~kb}$ flanking regions (tagging SNPs: rs5751862, rs2298383, rs3761422, rs2236624, 
Fig. 1 Pairwise linkage disequilibrium of 8 ADORA2A SNPs. a $D^{\prime}$, b $R^{2}$

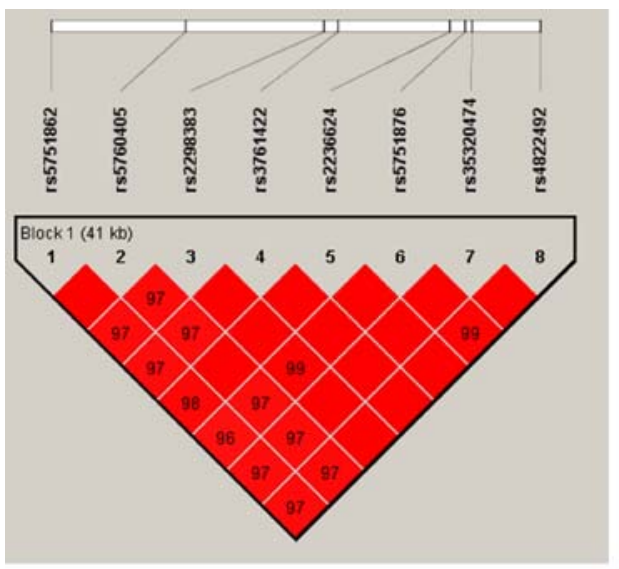

A $D^{\prime}$, empty cells stand for $D^{\prime}=1(100 \%)$

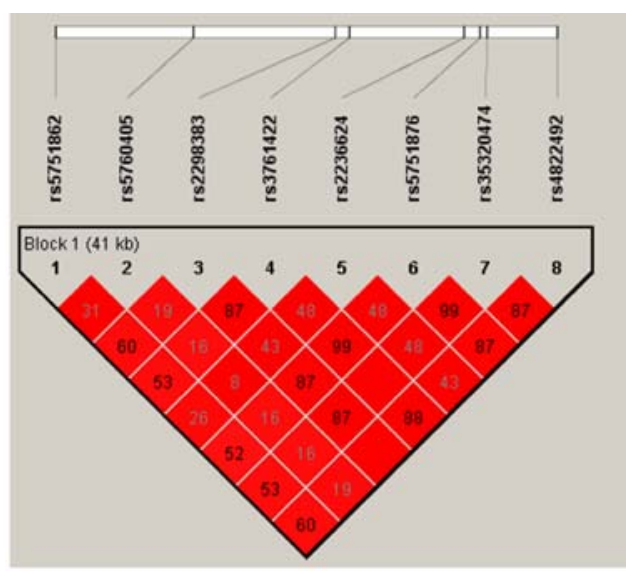

B $R^{2}$, empty cells stand for $R^{2}=1(100 \%)$ rs4822492; exonic SNPs: rs5760405 (263C/T), rs5751876 $(1976 \mathrm{C} / \mathrm{T})$, rs35320474 (2592T/-)). Genotyping was carried out as described previously $[1,7,10]$ except for SNPs rs2298383 and rs2236624. For these, standard PCR was carried out in $20 \mu \mathrm{l}$ volume, containing $60 \mathrm{ng}$ DNA, $10 \mathrm{pM}$ of each primer (MWG Biotech), $200 \mu \mathrm{M}$ dNTPs (Fermentas), 0.4 U Taq Polymerase (Eppendorf), $2.5 \mathrm{mM}$ $\mathrm{MgCl}_{2}$ (Eppendorf), $1 \times$ buffer (Eppendorf) and $\mathrm{H}_{2} \mathrm{O}$ : initial 5-min denaturation $\left(94^{\circ} \mathrm{C}\right)$ preceded 35 cycles $(30 \mathrm{~s}$ at $94^{\circ} \mathrm{C}, 30 \mathrm{~s}$ at $60^{\circ} \mathrm{C}$ and $60 \mathrm{~s}$ at $72^{\circ} \mathrm{C}$ ) and final extension $\left(10 \mathrm{~min}\right.$ at $72^{\circ} \mathrm{C}$; Biometra). The PCR products were restricted as recommended by the manufacturer (HpaII for rs2298383 and MnlI for rs2236624; Fermentas), separated on $15 \%$ polycrylamide gels (acrylamide:bisacrylamide $=$ $37.5: 1)$ at $230 \mathrm{~V} / \mathrm{cm}$ for $2 \mathrm{~h} \mathrm{RT}$ and visualized by silver staining. For genotyping quality control, randomized probands were re-genotyped $(N=41)$ or re-sequenced $(N=3)$ for all eight SNPs, resulting in concordance rates of $100 \%$ for both techniques. Genotyping yielded a completion rate of $100 \%$ in patients and control individuals except for one patient $(62.5 \%)$. All genotypes were determined to be blind to the disease status.

All SNPs were in Hardy-Weinberg equilibrium (HWE) in controls. SNPs rs5751862 $(P=0.061)$, rs2298383 $(P=0.064), \quad$ rs $2236624 \quad(P=0.026) \quad$ and $\quad$ rs 4822492 $(P=0.082)$ showed reduced heterozygosity in cases. Therefore, possible genomic gain or loss of ADORA2A was investigated by TaqMan-based quantitative real-time PCR (Applied Biosystems) focusing on SNP rs3761422, which is located between rs2298383 and rs2236624. PCRs were run in $10 \mu \mathrm{l}$ reactions as triplicates following the suppliers' recommendations. DNA concentrations were normalized to the three reference genes, 5HT1A (rs6295), RGS4 (rs10917671) and NPY (rs16474). Inter-assay variability (delta CT) between these genes and ADORA2A was determined using ten individuals recruited from the control sample. To normalize data, delta CT was calculated using as calibrator the mean of the respective delta CTs. Based on these controls, the mean haploid value was 1.01 with a standard deviation (SD) of 0.10. A conservative threefold SD threshold was used to assign a normal copy range of 0.71-1.31. Five ASD individuals were suspected of carrying a deletion (haploid value $<0.71$ ), and two of carrying an amplification (haploid value $>1.31$ ) within the ADORA2A locus. None of the control individuals showed a copy number variation (CNV) of ADORA2A. To control for false-positive findings due to possible CNVs in the ASD sample, statistical analyses were performed on the full sample as well as on the sample without these seven ASD individuals.

\section{Statistical analysis}

Descriptive data were compared by $t$ test, parametric or nonparametric analysis of variance, $\chi^{2}$ or Fisher's exact test as appropriate. Hardy-Weinberg equilibrium of SNPs in cases and controls, as well as pairwise linkage disequilibrium of SNPs $\left(D^{\prime}, R^{2}\right)$, was assessed by Haploview version 4.0 (http://www.broad.mit.edu/mpg/haploview). Association analyses of case/control status with genotypes were performed by $\chi^{2}$ tests. Haplotype association tests were done by Haploview version 4.0. Haplotypes from the eight SNPs were reconstructed on an individual level by PHASE, version 2.11 [26], based on a probability of reconstructed pairs of haplotypes for each individual $>0.99$. Haplotypes could not be reconstructed for two ASD and one control subject. Five haplotypes with a frequency of $>10 \%$ in cases and controls were assessed as either present or absent (ACTCCCTG, 44.4\%; ATTCCCTG, 40.1\%; GCCTCT-C, 28.0\%; GCCTTT-C, $37.7 \%$; GCTCCCTG, $21.9 \%$; as each individual carries two haplotypes, percentages sum up to a value of $<200 \%$ ). Exploratory association analyses of genoand haplotypes with variable phenotypic expression within the ASD group were performed by multivariate analysis of 
covariance (MANCOVA) with adjustment for sex, age, IQ and psychotropic/antiepileptic medication on the three dependent variables: ADI-R symptom domain scores of current social interaction, current non-verbal communication and current repetitive behavior. Current, but not age 4-5 years old, ADI-R symptom domain scores were chosen as dependent variables, as they are less likely to be inflated by reporting bias. MANCOVA residuals were normally distributed. Logistic regression analysis with adjustment for sex, age, IQ, and psychotropic/antiepileptic medication was performed to elicit the genetic influence on history of severe anxiety (ADI-R codings 2, 3). Statistics were calculated by SAS (SAS/STAT, version 8.2, Cary, BC: SAS Institute Inc., 1999-2001). Power analysis was performed by Quanto, version 1.2.3 (http://hydra.usc.edu/GxE).

\section{Results}

Descriptive data of the ASD sample are shown in Table 1. As expected from the diagnostic criteria, the three clinical groups differed with regard to IQ and autism-specific symptom severity. The sample was predominately a sample of high-functioning individuals with IQ $\geq 70(N=68$; 69.4\%). Two SNPs (rs2298383 and rs2236624) were nominally associated with ASD in the genetic case-control analysis (Table 2). The association was mainly due to reduced heterozygosity in ASD subjects. Due to reports of increased autistic traits in individuals with 22q11.2 deletion and the relatively frequent occurrence of CNVs throughout the genome in individuals with ASD [24], analysis was repeated for the ASD subgroup of 91 individuals without suspected deletion or amplification within the ADORA2A locus (see above). SNP rs2236624 remained nominally associated with $\operatorname{ASD}\left(\chi^{2}=8.0,2 d f, P=0.018\right)$ with higher rates of $\mathrm{CC}(71.1 \%)$ and reduced rates of $\mathrm{CT}$ (21.1\%), compared to controls. Global haplotype association analysis in the full and the reduced sample was negative (data not shown).

In the seven individuals with suspected $\mathrm{CNV}$ of ADORA2A, the frequency of rs5751862, rs5760405 and rs2236624 did not differ compared to controls. For rs2298383, rs3761422, rs5751876, rs35320474 and rs4822492 (Fisher's exact test $P_{(\text {all })}=0.010$ ), no heterozygote genotypes were observed; four individuals carried the more frequent homozygote genotype and three carried the less frequent homozygote genotype, respectively. Haplotype frequency did not differ from controls.

The contribution of $A D O R A 2 A$ to explain phenotypic variability within ASD individuals without suspected ADORA2A CNV was assessed by explorative association analyses of genotypes and haplotypes with ADI-R derived phenotypic measures and history of severe anxiety. In Table 3, results of the single SNP genotype analysis are reported. Increased ADI-R current social interaction, nonverbal communication and repetitive behavior scores (i. e., more autism-specific impairment) were observed in carriers of rs3761422-CT/TT, rs5751876-CT/TT and rs35320474-T-/-. These SNPs are tightly linked showing almost equal genotype frequencies in ASD (Table 2). The corresponding haplotype GCCTTT-C similarly showed a trend to be associated with autism-specific symptom

Table 1 Descriptive data

\begin{tabular}{|c|c|c|c|c|c|}
\hline & $\begin{array}{l}\text { Autism } \\
N=61 \\
(62.2 \%)\end{array}$ & $\begin{array}{l}\text { Asperger } \\
\text { syndrome } \\
N=25(25.5 \%)\end{array}$ & $\begin{array}{l}\text { Atypical autism } \\
N=12(12.2 \%)\end{array}$ & $\begin{array}{l}\text { Differences } \\
\text { between groups } \\
F(d f) / \chi^{2}(d f)\end{array}$ & $P$ value \\
\hline Females $[N(\%)]$ & $7(11.5)$ & $2(8.0)$ & $1(8.3)$ & & NS \\
\hline IQ [mean (SD)] & $78.2(25.7)$ & $101.4(17.8)$ & $79.7(18.2)$ & $15.1(2)$ & 0.0005 \\
\hline Age [mean (SD)] & $10.5(5.7)$ & $12.6(5.2)$ & $12.0(8.7)$ & & NS \\
\hline \multicolumn{6}{|l|}{ ADI-R algorithm social interaction [mean (SD)] } \\
\hline Current & $12.2(3.6)$ & $10.2(5.2)$ & $6.2(4.4)$ & $11.1(2)$ & $<0.0001$ \\
\hline Age $4-5$ years old & $19.9(5.3)$ & $16.4(5.4)$ & $14.8(5.6)$ & $6.0(2)$ & 0.004 \\
\hline \multicolumn{6}{|c|}{ ADI-R algorithm non-verbal communication [mean (SD)] } \\
\hline Current & $8.8(3.8)$ & $4.2(2.9)$ & $3.6(3.6)$ & $17.3(2)$ & $<0.0001$ \\
\hline Age $4-5$ years old & $10.8(2.8)$ & $6.5(3.2)$ & $5.7(3.1)$ & $24.0(2)$ & $<0.0001$ \\
\hline \multicolumn{6}{|l|}{ ADI-R algorithm repetitive behavior [mean (SD)] } \\
\hline Current & $5.9(2.6)$ & $4.7(2.1)$ & $3.4(3.1)$ & $5.4(2)$ & 0.006 \\
\hline Age $4-5$ years old & $7.0(2.6)$ & $5.3(2.1)$ & $4.9(3.7)$ & $4.8(2)$ & 0.010 \\
\hline ADI-R history of severe anxiety $[N(\%)]$ & $12(19.7)$ & $5(20.0)$ & $2(16.7)$ & & NS \\
\hline Psychotropic or antiepileptic medication $[N(\%)]$ & $15(24.6)$ & $3(12.0)$ & $12(16.7)$ & & NS \\
\hline
\end{tabular}

$d f$ degrees of freedom; $F, F$ value; $S D$ standard deviation; NS, $P>0.10$ 
Table 2 Genotypes in cases and controls

\begin{tabular}{|c|c|c|c|c|c|}
\hline SNP & Localization & $\begin{array}{l}\text { ASD } \\
(N=98) \\
N(\%)\end{array}$ & $\begin{array}{l}\text { Controls } \\
(N=234) \\
N(\%)\end{array}$ & $\begin{array}{l}\text { Differences } \\
\text { between groups } \\
\chi^{2}(d f)\end{array}$ & $P$ value \\
\hline rs5751862 & $9.5 \mathrm{~kb}, 5^{\prime}$ flank & $\begin{array}{l}\text { AA } 30(30.6) \\
\text { AG } 39(39.8) \\
\text { GG } 29(26.6)\end{array}$ & $\begin{array}{l}\text { AA } 57(24.4) \\
\text { AG } 117(50.0) \\
\text { GG } 60(25.6)\end{array}$ & $3.0(2)$ & 0.227 \\
\hline rs5760405 (263C/T) & Exon I & $\begin{array}{l}\text { CC } 58(59.2) \\
\text { CT } 31(31.6) \\
\text { TT } 9(9.2)\end{array}$ & $\begin{array}{l}\text { CC } 140(59.8) \\
\text { CT } 79(33.8) \\
\text { TT } 15(6.4)\end{array}$ & $0.8(2)$ & 0.659 \\
\hline rs 2298383 & Intron I & $\begin{array}{l}\text { CC } 18(18.6) \\
\text { CT } 36(37.1) \\
\text { TT } 43(44.3)\end{array}$ & $\begin{array}{l}\text { CC } 33(14.1) \\
\text { CT } 122(52.1) \\
\text { TT } 79(33.8)\end{array}$ & $6.2(2)$ & $0.045^{*}$ \\
\hline rs3761422 & Intron I & $\begin{array}{l}\text { CC } 45(45.9) \\
\text { CT } 38(38.8) \\
\text { TT } 15(15.3)\end{array}$ & $\begin{array}{l}\text { CC } 89(38.0) \\
\text { CT } 117(50.0) \\
\text { TT } 28(12.0)\end{array}$ & $3.5(2)$ & 0.172 \\
\hline rs2236624 & Intron IV & $\begin{array}{l}\text { CC } 69(71.1) \\
\text { CT } 21(21.7) \\
\text { TT } 7(7.2)\end{array}$ & $\begin{array}{l}\text { CC } 136(58.1) \\
\text { CT } 87(37.1) \\
\text { TT } 11(4.7)\end{array}$ & $7.7(2)$ & $0.021 *$ \\
\hline rs5751876 (1976C/T) & Exon 5 & $\begin{array}{l}\text { CC } 44(44.9) \\
\text { CT } 39(39.8) \\
\text { TT } 15(15.3)\end{array}$ & $\begin{array}{l}\text { CC } 89(38.0) \\
\text { CT } 117(50.0) \\
\text { TT } 28(12.0)\end{array}$ & $2.9(2)$ & 0.230 \\
\hline rs35320474 (2592T/-) & Exon 5 & $\begin{array}{l}-15(15.5) \\
\text { T- } 37(28.1) \\
\text { TT } 45(46.4)\end{array}$ & $\begin{array}{l}-28(12.0) \\
\text { T- } 117(50.0) \\
\text { TT } 89(38.0)\end{array}$ & $3.9(2)$ & 0.142 \\
\hline rs4822492 & $5.5 \mathrm{~kb} 3^{\prime}$ flank & $\begin{array}{l}\text { CC } 18(18.4) \\
\text { CG } 37(37.8) \\
\text { GG } 43(43.9)\end{array}$ & $\begin{array}{l}\text { CC } 33(14.1) \\
\text { CG } 122(52.1) \\
\text { GG } 79(33.8)\end{array}$ & $5.7(2)$ & 0.057 \\
\hline
\end{tabular}

$d f$ degrees of freedom

$* P<0.05$

presence of haplotype ACTCCCTG in the CNV group $(57.1 \%)$.

more often in carriers of haplotype ACTCCCTG (Table 4). Of the individuals with history of severe anxiety, $73.3 \%$ carried this haplotype, whereas of the individuals without anxiety, only $33.9 \%$ carried haplotype ACTCCCTG. The correct classification was $76.6 \%$. No association of anxiety with single SNPs was observed.

Of the seven ASD individuals with suspected CNV within the ADORA2A locus, four carried a diagnosis of autism and three a diagnosis of Asperger syndrome; all were male. When these individuals were compared to the 91 ASD individuals without suspected ADORA2A CNV with regard to phenotypic measures, the following differences were found: IQ (mean 73.0; SD 17.5) was slightly lower in the suspected CNV group. Similarly, ADI-R current social interaction (mean 12.0; SD 2.6), verbal (mean 15.2; SD 2.5) and non-verbal (mean 8.8; SD 1.5) as well as repetitive behavior scores (mean 6.6; SD 1.1) were slightly increased in the CNV group; however, the differences did not approach significance. The rate of history of severe anxiety, however, was significantly increased $(P<0.0001)$, possibly due to the relatively frequent

\section{Discussion}

In this study, eight SNPs in the ADORA2A locus on chromosome $22 \mathrm{q} 11.23$ were assessed in 98 Caucasian individuals with ASD without dysmorphic features and sex-matched Caucasian control subjects. The strength of this study is its rigorous phenotyping of ASD individuals to increase phenotypic homogeneity and reduce rates of phenocopies and syndromic ASD in case-control analysis. To control for possible small CNVs within the ADORA2A locus not observed by standard cytogenetic testing, TaqMan-based quantitative PCR was performed. Seven ASD individuals $(7 \%)$ were suspected of potentially carrying a small CNV. This seems to be relatively high, compared to the reported rate of $7-44 \% \mathrm{CNVs}$ in a genome-wide analysis [16, 24], taking into account the expected differing $\mathrm{CNV}$ rates of locus- versus genome-wide studies. It might be due to the conservative cutoff of 3 SD used in the study, 
Table 3 Association of genotypes with phenotypic variability in ASD subjects without suspected CNV

\begin{tabular}{|c|c|c|c|}
\hline & rs 3761422 & rs5751876 & rs35320474 \\
\hline ADI-R algorithm current social interaction score & CC $9.7(1.2)$ & CC $9.7(1.2)$ & $-12.7(1.6)$ \\
\hline \multirow[t]{2}{*}[\operatorname{mean}^{\mathrm{a}}(\mathrm{SE})]{} & CT $13.5(1.3)$ & CT $13.5(1.3)$ & T- $13.3(1.2)$ \\
\hline & TT $12.6(1.7)$ & TT $12.6(1.7)$ & TT $9.7(1.1)$ \\
\hline ADI-R algorithm current non-verbal communication score & CC $5.9(1.1)$ & CC $5.9(1.1)$ & $-8.8(1.5)$ \\
\hline \multirow[t]{2}{*}[\operatorname{mean}^{\mathrm{a}}(\mathrm{SE})]{} & CT $8.2(1.2)$ & CT $8.2(1.2)$ & T- $8.0(1.2)$ \\
\hline & TT $8.7(1.5)$ & TT $8.7(1.5)$ & TT $5.9(1.1)$ \\
\hline ADI-R algorithm current repetitive behavior score & CC $3.9(0.7)$ & CC $3.9(0.7)$ & $-5.6(1.0)$ \\
\hline \multirow[t]{2}{*}[\operatorname{mean}^{\mathrm{a}}(\mathrm{SE})]{} & CT $5.3(0.7)$ & СТ $5.3(0.7)$ & T- $5.2(0.7)$ \\
\hline & TT $5.7(1.0)$ & TT $5.7(1.0)$ & TT $3.9(0.7)$ \\
\hline MANCOVA & $0.83,2.4(6,140)$ & $0.83,2.4(6,140)$ & $0.83,2.2(6,138)$ \\
\hline Wilks-Lambda, $F$ (Num $d f$, Den $d f$ ), $P$ value & 0.033 & 0.034 & 0.040 \\
\hline
\end{tabular}

Only SNPs associated with phenotypic variability (MANCOVA $P$ value $<0.050$ ) are reported. No association was observed of single SNPs with history of severe anxiety, current hyperactivity or history of epilepsy

$d f$ degrees of freedom; $F, F$ value; MANCOVA multivariate analysis of covariance; $S E$ standard error of mean

${ }^{a}$ Mean value adjusted for age, sex, IQ and medication status

Table 4 Association of haplotypes with phenotypic variability in ASD subjects without suspected CNV

\begin{tabular}{|c|c|c|}
\hline & $\begin{array}{l}\text { Haplotype } \\
\text { ACTCCCTG } \\
N=40(44.0 \%)\end{array}$ & $\begin{array}{l}\text { Haplotype } \\
\text { GCCTTT-C } \\
N=27(29.7 \%)\end{array}$ \\
\hline ADI-R algorithm current social interaction score & & (1) 12.5 (1.4) \\
\hline$\left[\operatorname{mean}^{\mathrm{a}}(\mathrm{SE})\right]$ & & (0) $10.9(1.1)$ \\
\hline ADI-R algorithm current non-verbal communication score & & (1) $9.1(1.2)$ \\
\hline$\left[\operatorname{mean}^{\mathrm{a}}(\mathrm{SE})\right]$ & & (0) $6.4(1.0)$ \\
\hline ADI-R algorithm current repetitive behavior score & & (1) $5.4(0.8)$ \\
\hline$\left[\operatorname{mean}^{\mathrm{a}}(\mathrm{SE})\right]$ & & (0) $4.4(0.6)$ \\
\hline MANCOVA Wilks-Lambda, $F$ value (Num, Den $d f$ ), $P$ value & & $0.9,2.5(3,70) 0.065$ \\
\hline ADI-R history of severe anxiety & $\begin{array}{l}\mathrm{OR}=5.5 \\
(95 \% \text { CI } 1.5-20.6)\end{array}$ & \\
\hline Statistic: Wald $\chi^{2}(d f) P$ value & $6.5(1) 0.011$ & \\
\hline
\end{tabular}

Lowest $P$ values for MANCOVA on ADI-R scores were reported. For history of severe anxiety, only the haplotype associated with phenotypic variability $(P$ value $<0.050)$ is reported

(1) haplotype present, (0) haplotype not present

$C I$ confidence interval; $d f$ degrees of freedom; $F, F$ value; $S E$ standard error of mean; $O R$ Odds ratio, adjusted for age, sex, IQ and medication status

${ }^{\text {a }}$ Mean value adjusted for age, sex, IQ and medication status

which was chosen to exclude individuals with a possible CNV from the association study to prevent false-positive findings. In addition, the TaqMan-based technology allows the detection of smaller CNVs in the size of a few kilobases compared to the previously applied comparative genomic hybridization technology. As ADORA2A duplications or deletions have neither been reported in the database of genomic variants (http://projects.tcag.ca/variation) nor in this control sample, but large deletions and duplications of 22q11.2 have been observed in individuals with ASD [16], these preliminary findings support the notion that ADORA2A or other closely located genes might be of relevance to ASD. Our rigorous, conservative approach resulted in limited power to detect genetic risk factors of minor effects in case-control analysis. Only a genetic relative risk between 1.9 (minor allele frequency 0.14-0.17) and 1.7 (minor allele frequency $>0.26$ ) could be detected with a power of $>0.80$ in the sample of 91 individuals without suspected CNVs. The nominal association of rs2236624-CC as risk genotype with an odds ratio of 1.6 
(95\% CI 1.3-2.3) compared to CT, therefore, might have occurred by chance and needs to be replicated in a larger sample with sufficient power. rs2236624 is located in intron IV, but has been reported to show intermediate regulatory potential (http://genome.ucsc.edu). It is in strong LD with neighboring SNPs, of which rs 2298383 and rs3761422 might be located in one of the potential promoter regions upstream of several newly identified ADORA2A exon 1 variants, and therefore might be functionally relevant [31].

Single SNPs and haplotypes, additionally, were nominally associated with parent-reported phenotypic variability within ASD subjects. The observed findings have to be viewed with caution, as parental report of autistic symptoms might be biased and the findings do not withstand multiple testing. History of severe anxiety was associated with haplotype ACTCCCTG, but not with genotypes of single SNPs. Previous studies on panic disorder and anxiety reported preferential transmission of the rs5751876 C-allele and also co-segregation of the $\mathrm{T}$-allele in some families in a family-based study [9], or reported the T-allele as risk allele for anxiety induced by D-amphetamine or caffeine $[6,11]$ and panic disorder [7]. These findings might be indicative of a functional variant in strong LD with rs 5751876 increasing the risk for anxiety not only in healthy or panic disorder subjects, but also in individuals with ASD. The additional findings of our study have to be interpreted in a hypothesesgenerating way. The nominal association with autism-specific symptom severity of three tightly linked SNPs and the corresponding haplotype does not correspond to the nominally associated intronic rs2236624 and might have occurred by chance only. Results again need to be replicated in larger sample with increased power.

The limitations of the study are first related to the control group, which was not screened explicitly for ASDs. This might have resulted in reduced power, as prevalence of ASD was estimated around 1\% [3]. In addition, population stratification cannot fully be excluded; however, inclusion of Caucasian individuals only argues against the strong effects of population stratification. The possible role of ADORA2A variants in the pathogenesis of ASD is emphasized by the association of single SNPs with phenotypic variability in ASD subjects. The observed associations did not withstand multiple testing. However, as all SNPs were in strong LD, and the three SNPs that were associated with increased autism-specific psychopathology did show almost similar genotype frequencies, Bonferroni correction would have underestimated a true association and would have resulted in the risk of false-negative reporting.

Taken together, we reported a nominal association of ADORA2A rs2236624 with ASD and replicated ADORA2A variants as risk factors for anxiety not only in healthy, but also in ASD individuals. The findings of this study need to be replicated in a larger sample with sufficient power to also detect variants with a small genetic relative risk.

Acknowledgments We thank the participating individuals for taking part in the study. The study was supported by grant T6 0310 $00-45$ of the Saarland University to Christine M. Freitag.

Conflict of interest statement None of the authors has any conflicts of interest.

\section{References}

1. Alsene K, Deckert J, Sand P, de Wit H (2003) Association between A2a receptor gene polymorphisms and caffeine-induced anxiety. Neuropsychopharmacology 28:1694-1702

2. American Psychiatric Association (1994) Diagnostic and statistical manual of mental disorders (DSM-IV), 4th edn. American Psychiatric Association, Washington, DC

3. Baird G, Simonoff E, Pickles A, Chandler S, Loucas T, Meldrum D, Charman T (2006) Prevalence of disorders of the autism spectrum in a population cohort of children in South Thames: the special needs and autism project (SNAP). Lancet 368:210-215

4. Bolte S, Poustka F (2004) The German form of the autism diagnostic observation schedule (ADOS): first results on reliability and validity. Zeitschrift fur Kinder-und Jugendpsychiatrie und Psychotherapie 32:45-50

5. Chen JF, Moratalla R, Impagnatiello F, Grandy DK, Cuellar B, Rubinstein M, Beilstein MA, Hackett E, Fink JS, Low MJ, Ongini E, Schwarzschild MA (2001) The role of the $D(2)$ dopamine receptor $(\mathrm{D}(2) \mathrm{R})$ in $\mathrm{A}(2 \mathrm{~A})$ adenosine receptor $(\mathrm{A}(2 \mathrm{~A}) \mathrm{R})$-mediated behavioral and cellular responses as revealed by $\mathrm{A}(2 \mathrm{~A})$ and D(2) receptor knockout mice. Proc Natl Acad Sci USA 98:19701975

6. Childs E, Hohoff C, Deckert J, Xu K, Badner J, de Wit H (2008) Association between ADORA2A and DRD2 polymorphisms and caffeine-induced anxiety. Neuropsychopharmacology 33:27912800

7. Deckert J, Nothen MM, Franke P, Delmo C, Fritze J, Knapp M, Maier W, Beckmann H, Propping P (1998) Systematic mutation screening and association study of the A1 and A2a adenosine receptor genes in panic disorder suggest a contribution of the $\mathrm{A} 2 \mathrm{a}$ gene to the development of disease. Mol Psychiatry 3:81-85

8. Freitag CM (2007) The genetics of autistic disorders and its clinical relevance: a review of the literature. Mol Psychiatry $12: 2-22$

9. Hamilton SP, Slager SL, De Leon AB, Heiman GA, Klein DF, Hodge SE, Weissman MM, Fyer AJ, Knowles JA (2004) Evidence for genetic linkage between a polymorphism in the adenosine $2 \mathrm{~A}$ receptor and panic disorder. Neuropsychopharmacology 29:558-565

10. Hohoff C, Marziniak M, Lesch KP, Deckert J, Sommer C, Mossner R (2007) An adenosine A2A receptor gene haplotype is associated with migraine with aura. Cephalalgia 27:177-181

11. Hohoff C, McDonald JM, Baune BT, Cook EH, Deckert J, de Wit $\mathrm{H}$ (2005) Interindividual variation in anxiety response to amphetamine: possible role for adenosine A2A receptor gene variants. Am J Med Genet B Neuropsychiatr Genet 139:42-44

12. Koles L, Wirkner K, Illes P (2001) Modulation of ionotropic glutamate receptor channels. Neurochem Res 26:925-932

13. Leyfer OT, Folstein SE, Bacalman S, Davis NO, Dinh E, Morgan J, Tager-Flusberg H, Lainhart JE (2006) Comorbid psychiatric disorders in children with autism: interview development and rates of disorders. J Autism Dev Disord 36:849-861 
14. Lord C, Risi S, Lambrecht L, Cook E H Jr, Leventhal BL, DiLavore PC, Pickles A, Rutter M (2000) The autism diagnostic observation schedule-generic: a standard measure of social and communication deficits associated with the spectrum of autism. J Autism Dev Disord 30:205-223

15. Lord C, Rutter M, Le Couteur A (1994) Autism diagnostic interview-revised: a revised version of a diagnostic interview for caregivers of individuals with possible pervasive developmental disorders. J Autism Dev Disord 24:659-685

16. Marshall CR, Noor A, Vincent JB, Lionel AC, Feuk L, Skaug J, Shago M, Moessner R, Pinto D, Ren Y, Thiruvahindrapduram B, Fiebig A, Schreiber S, Friedman J, Ketelaars CE, Vos YJ, Ficicioglu C, Kirkpatrick S, Nicolson R, Sloman L, Summers A, Gibbons CA, Teebi A, Chitayat D, Weksberg R, Thompson A, Vardy C, Crosbie V, Luscombe S, Baatjes R, Zwaigenbaum L, Roberts W, Fernandez B, Szatmari P, Scherer SW (2008) Structural variation of chromosomes in autism spectrum disorder. Am J Hum Genet 82:477-488

17. Melchers, P., Preuß, U. (2001) Kaufman assessment battery for children, German version, 6th edn. Hogrefe, Göttingen

18. Moreau JL, Huber G (1999) Central adenosine A(2A) receptors: an overview. Brain Res Brain Res Rev 31:65-82

19. Pardo CA, Eberhart CG (2007) The neurobiology of autism. Brain Pathol 17:434-447

20. Poustka F, Lisch S, Ruhl D, Sacher A, Schmotzer G, Werner K (1996) The standardized diagnosis of autism, autism diagnostic interview-revised: interrater reliability of the German form of the interview. Psychopathology 29:145-153

21. Retey JV, Adam M, Honegger E, Khatami R, Luhmann UF, Jung HH, Berger W, Landolt HP (2005) A functional genetic variation of adenosine deaminase affects the duration and intensity of deep sleep in humans. Proc Natl Acad Sci USA 102:15676-15681

22. Schiffmann SN, Fisone G, Moresco R, Cunha RA, Ferre S (2007) Adenosine $\mathrm{A}(2 \mathrm{~A})$ receptors and basal ganglia physiology. Prog Neurobiol 83:277-292
23. Schneider T, Ziolkowska B, Gieryk A, Tyminska A, Przewlocki $R$ (2007) Prenatal exposure to valproic acid disturbs the enkephalinergic system functioning, basal hedonic tone, and emotional responses in an animal model of autism. Psychopharmacology (Berl) 193:547-555

24. Sebat J, Lakshmi B, Malhotra D, Troge J, Lese-Martin C, Walsh T, Yamrom B, Yoon S, Krasnitz A, Kendall J, Leotta A, Pai D, Zhang R, Lee YH, Hicks J, Spence SJ, Lee AT, Puura K, Lehtimaki T, Ledbetter D, Gregersen PK, Bregman J, Sutcliffe JS, Jobanputra V, Chung W, Warburton D, King MC, Skuse D, Geschwind DH, Gilliam TC, Ye K, Wigler M (2007) Strong association of de novo copy number mutations with autism. Science 316:445-449

25. Stanfield AC, McIntosh AM, Spencer MD, Philip R, Gaur S, Lawrie SM (2008) Towards a neuroanatomy of autism: a systematic review and meta-analysis of structural magnetic resonance imaging studies. Eur Psychiatry 23:289-299

26. Stephens M, Donnelly P (2003) A comparison of bayesian methods for haplotype reconstruction from population genotype data. Am J Hum Genet 73:1162-1169

27. Tellegen PJ, Winkel M, Laros JA (1998) SON-R 2 1/2-7. Nonverbaler Intelligenztest

28. Tewes U, Neubauer A, von Aster M (2006) WIE. Wechsler Intelligenztest für Erwachsene

29. Tewes U, Rossmann P, Schallberger U (2000) HAWIK-III. Hamburg-Wechsler-Intelligenztest für Kinder III

30. Vorstman JA, Morcus ME, van Engeland H (2007) Autism in children with 22q11.2 deletion syndrome. J Am Acad Child Adolesc Psychiatry 46:434-435

31. Yu L, Frith MC, Suzuki Y, Peterfreund RA, Gearan T, Sugano S, Schwarzschild MA, Weng Z, Fink JS, Chen JF (2004) Characterization of genomic organization of the adenosine $\mathrm{A} 2 \mathrm{~A}$ receptor gene by molecular and bioinformatics analyses. Brain Res 1000:156-173 